\title{
Arte, experiência e criação: as linguagens artísticas no Colégio Universitário da UFMA
}

Micael Carvalho dos Santos* Beatriz de Jesus Sousa**

\section{Resumo:}

Este artigo apresenta algumas experiências artísticas de organização do trabalho pedagógico em Artes do Colégio Universitário da Universidade Federal do Maranhão (COLUN/UFMA), com ênfase nas atividades extracurriculares. Utiliza o relato de experiência para pontuar ações nas linguagens de Artes Visuais, Música e Teatro. Este estudo envolve uma discussão sobre o ensino de Arte e possibilidades de experimentações estéticas nos diversos espaços do ambiente escolar. Como resultados que envolvem essas atividades, destaca-se o envolvimento dos estudantes ativamente nas diferentes linguagens artísticas, desenvolvendo habilidades específicas de cada linguagem e atravessadas pela interdisciplinaridade. Destaca-se a maior afetividade dos discentes e docentes participantes dos espaços artísticos, na exploração das potencialidades de criação, autonomia, desenvolvimento de expressividades individuais e coletivas.

\section{Palavras-chave:}

Ensino de Arte. Linguagens artísticas. COLUN/UFMA.

\begin{abstract}
:
The present paper presents some artistic experiences of organizing the pedagogical work in Arts of the Colégio Universitário of Universidade Federal do Maranhão (COLUN/UFMA) with emphasis on extracurricular activities. It uses the experience report to propose actions in the languages of Visual Arts, Music and Theater. This study involves a discussion on the teaching of Art and the possibilities of aesthetic experimentation in the different spaces of the school. As results that involve these activities, students' involvement in different artistic languages stands out, developing specific skills of each language and permeated by interdisciplinarity. A greater affection of the students and teachers participating in artistic spaces also stands out, in exploring the potential of creation, autonomy and development of individual and collective expressions.
\end{abstract}

\section{Keywords:}

Art teaching. Artistic languages. COLUN/UFMA.

\footnotetext{
* Mestre em Educação pela UFMA, Professor do Colégio de Aplicação UFMA. E-mail: micaelmusic@gmail.com. ORCID iD: http://orcid.org/0000-0001-5802-9015.

${ }^{* *}$ Mestra em Cultura e Sociedade pela UFMA. E-mail: beatrizdejesussousa@yahoo.com.br. ORCID iD: http://orcid.org/0000-0002-9497-9330.
} 


\section{Introdução}

O presente texto sistematiza algumas experiências artísticas de organização pedagógica em Artes do Colégio Universitário da Universidade Federal do Maranhão (COLUN/UFMA). Para tanto, partimos da compreensão do currículo em sua gênese como busca de compreensão e organização do processo educativo escolar (MOREIRA; TADEU, 2011). Além disso, à luz de Giroux e Simon (2011), buscamos relacionar brevemente currículo, cultura e sociedade, destacando a importância da pedagogia crítica por meio da análise de relações potencialmente transformadoras resultantes de atividades artísticas.

Na primeira parte, discutimos as tessituras sonoras, visuais e corporais pensando o currículo como um movimento contínuo. Um artefato social vivo, que organiza o processo da educação escolar de diversas formas, refletindo sobre suas epistemologias a partir das diversas teorias curriculares construídas ao longo da história. Nesse movimento, esboçamos o lugar da Arte no contexto de cultura escolar comum, uniforme e homogênea para provocar a necessidade das ações que buscam refletir a pluralidade existente.

Apresentamos, desse modo, algumas ações do COLUN/UFMA que visam expandir as possibilidades de ampliação das experiências artísticas no espaço escolar.

\section{Tessituras sonoras, visuais e corporais: o currículo em movimento}

Currículo é lugar, espaço, território. O currículo é relação de poder. O currículo é trajetória, viagem, percurso. O currículo é autobiografia, nossa vida, curriculum vitae: no currículo se forja nossa identidade. O currículo é texto, discurso, documento. O currículo é documento de identidade. (SILVA, 1999, p. 150).

Ao sintetizar o currículo em poucas palavras, mas de grande expressividade na compreensão das teorias curriculares, Silva (1999) nos provoca a pensar a potencialidade das práticas pedagógicas inseridas em múltiplos contextos do espaço educativo. Apesar da gênese do currículo como busca do alinhamento das instituições escolares aos processos de reconfiguração do processo produtivo nos EUA (MOREIRA; TADEU, 2011), os estudos curriculares atravessaram - e atravessam - debates constantes devido sua fundamentação com a vida materializada nos sujeitos construtores das relações de poder.

Para Silva (1999) as teorias curriculares têm sido classificadas em três: tradicionais, críticas e pós-críticas, com questões centrais sobre qual conhecimento deve ser constituído e para qual finalidade no processo ensino/aprendizado. Além das teorias, podemos perceber que as tessituras que formam a natureza da organização do conhecimento escolar podem se apresentar com o cotidiano (currículo em ação) e também com os aspectos não explicitados no currículo oficial que fazem parte da experiência educacional.

Sob as perspectivas das relações entre currículo, cultura e sociedade, podemos conceber o currículo escolar como um artefato social, fundamentado nas relações de poder, socialização de experiências e construção de identidades. Giroux e Simon (2011) destacam a importância da pedagogia crítica por meio de sua análise das relações potencialmente transformadoras e, desse modo, "[...] importante espaço pedagógico em que são levantadas relevantes questões sobre os elementos que organizam a base da subjetividade e da experiência do aluno" (GIROUX; SIMON, 2011, p. 110).

O lugar da Arte no currículo escolar atravessa movimentos de avanços e retrocessos se pensarmos do ponto de vista das políticas públicas de educação. Em especial, este componente curricular é resultado de um intenso processo de articulação e persistências de arte-educadores comprometidos com a qualidade do ensino em consonância com o desenvolvimento pleno das expressividades artísticas na escola.

Percebemos algumas conquistas na Lei de Diretrizes e Bases da Educação Nacional (Lei 9394/1996), nos Parâmetros Curriculares Nacionais (PCN) e também na Lei 13.278, de 2016 (altera o artigo 26 da LDB), que estabelece as Artes Visuais, a Dança, a Música e o Teatro como linguagens que constituem o componente curricular Arte. Apesar do desmonte de várias políticas educacionais a partir das (contra)reformas pós-golpe 
no Brasil, em 2016, destacando sobretudo a Lei 13.415, de 2017 (Reforma do Ensino Médio), arte-educadores e instituições escolares públicas têm se manifestado e se movimentado no sentido contrário às exclusões e marginalizações das linguagens artísticas e também dos conteúdos da diversidade e pluralidade trazidos e provocados por elas, como gênero, sexualidade, raça, etnia, dentre outros.

A cultura escolar dominante em nossas instituições educativas prioriza o comum, o uniforme, o homogêneo, conforme sinaliza Candau (2011). Nesse sentido, provocar as diferentes expressividades em sintonia com a pluralidade configura-se como ação pedagógica contra hegemônica, diferente e potencialmente significativa na cultura escolar.

Por se tratar de espaços de referência na organização curricular e na qualidade de ensino da educação básica pública, os Colégios de Aplicação se constituem também como campo de experiências múltiplas estabelecendo diálogos entre currículo e formação docente. No campo da Arte tem avançado para a consolidação do trabalho com as expressividades artísticas e na iniciativa de projetos coletivos.

O potencial dos Colégios de Aplicação se estabelece pela possibilidade de abertura e autonomia na construção dos percursos formativos, incluindo iniciativas que estão "fora" do dito currículo formal (currículo oculto e o currículo em ação). Se constitui como possível e necessariamente importante pela qualificação docente e por financiamento que garanta o desenvolvimento dos trabalhos artísticos dentro e fora do espaço escolar.

O Colégio Universitário da Universidade Federal do Maranhão tem construído sua identidade no campo artístico pelas iniciativas que rompem com a disciplinaridade sem ser tomado pela polivalência. Cada docente e cada linguagem possui seu espaço físico e pedagógico, suas experiências individuais e coletivas, integrando a Arte como produção humana e fundamentada na capacidade criativa dos discentes partícipes do processo educativo humanizado, crítico e capaz de intervir na realidade com reflexões sobre a vida e, também, com crítica à vida.

Desse modo, por se tratar de um trabalho em formato de relato de experiências, destacaremos algumas das iniciativas desenvolvidas, nos últimos anos, pelo campo da Arte no Colégio de Aplicação da UFMA.

\section{Arte, experiência e criação}

As diversas experiências artísticas no espaço escolar proporcionam aos sujeitos envolvidos no processo (docentes e discentes) condições educativas de pensar e repensar formas, conceitos e abordagens plurais para a construção de identidades, memórias e aprendizados significativos. Destacamos, desse modo, experiências por linguagens e também iniciativas coletivas da Arte no COLUN que podem expressar potencialidades do fazer artístico na educação básica.

\section{Festival de Artes "50 tons, sons e expressões"}

Realizado em 2018 com todas as turmas do Ensino Fundamental e Médio, o evento teve como temática os 50 anos do Colégio Universitário da UFMA. As músicas, desenhos, pinturas, fotografias, instalações, vídeos, poesias, apresentações de teatro e dança seguiram essa orientação temática ou estiveram relacionadas à experiência dos estudantes na escola. O Festival teve como objetivo fomentar a expressão artística e poética dos estudantes da escola sobre o aniversário de 50 anos do COLUN, contribuindo para o desenvolvimento da leitura crítica e da sensibilidade dos estudantes sobre a importância da escola pública de qualidade, sentindo-se comprometidos com o processo de construção do conhecimento por meio da historicidade da sua instituição escolar. 


\section{Festival de Artes "Povos indígenas no Maranhão: cultura e resistência"}

O II Festival de Artes do COLUN/UFMA, edição 2019, teve como temática "Povos Indígenas: cultura e resistência”, sendo uma proposta da área de linguagens, com trabalhos pedagógicos de cunho artístico, acompanhados pelos professores de Arte e orientados pelos demais docentes da área. As modalidades para este festival foram: expressividade musical, linguagem audiovisual, animação, artesanato, grafismo e pintura, trançado e cestaria, instalação artística, exposição fotográfica e expressões cênicas nos rituais, no dia 6 de dezembro de 2019, com ensaio geral no dia 5, véspera do evento. O projeto teve como objetivo contribuir para o desenvolvimento da leitura crítica e da sensibilidade dos estudantes sobre a importância dos povos originários, sentindo-se comprometidos com o processo de garantias de direitos, respeito à diversidade e valorização dos saberes tradicionais. Como etapa preparatória para o Festival, foram realizadas atividades que incluíram debates, minicurso, roda de conversa e oficina, como meio de formação docente na temática proposta. Por meio dos estudos e atividades desenvolvidos, pretendeu-se promover a sensibilização no ambiente escolar, envolvendo todos os níveis de ensino em relação à importância e valorização dos povos indígenas no Maranhão.

\section{Musical Vozes de uma geração: histórias da MPB}

A atividade foi realizada no segundo semestre de 2017, integrada ao plano de ensino curricular de Música com as turmas do Terceiro Ano do Ensino Médio (4 turmas - 103 alunos), coordenada pelo professor de música do COLUN/UFMA. Ainda, o processo envolveu 08 estagiários do curso de Licenciatura em Música e 01 supervisora de Estágio, professora do curso de Licenciatura em Música da UFMA. A ação foi construída coletivamente, envolvendo todos os sujeitos, sempre buscando estabelecer relações horizontais, para que todos pudessem participar ativamente das decisões. $\mathrm{O}$ trabalho buscou articular as diferentes linguagens artísticas (Música, Dança, Teatro, Artes Visuais), visando a elaboração de um espetáculo, do gênero musical, sobre alguns dos principais movimentos da Música Popular Brasileira do século XX. Ainda, visou envolver os estudantes ativamente na capacidade criativa, tomada de decisões, compreensão estilística/estética e reconhecimento sobre a contextualização histórica e política dos diferentes movimentos da MPB abordados no Musical.

\section{Quadro 1 - Organização do repertório por movimento}

\begin{tabular}{|c|c|}
\hline \multicolumn{2}{|r|}{ Organização do repertório por movimento } \\
\hline Jovem Guarda & $\begin{array}{l}\text { - Pot-pourri: Banho de Lua (Celly Campello); Biquíni de Bolinha Amarelinha } \\
\text { (Blitz); Ele é o Bom (Roberto Carlos/Eduardo Araújo); } \\
\text { - Pare o Casamento (Wanderléa) } \\
\text { - Gatinha Manhosa (Erasmo Carlos) }\end{array}$ \\
\hline Música de Protesto & $\begin{array}{l}\text { - Cálice (Chico Buarque); } \\
\text { - Pra não dizer que não falei das flores (Geraldo Vandré) } \\
\text { - Opinião (Zé Keti) } \\
\text { - Oração Latina (César Teixeira) }\end{array}$ \\
\hline Clube da Esquina & $\begin{array}{l}\text { - Travessia (Milton Nascimento/Fenando Brant) } \\
\text { - Para Lennon e McCartney (Milton Nascimento/Lo Borges) } \\
\text { - Maria, Maria (Milton Nascimento/Fernando Brant) }\end{array}$ \\
\hline Tropicália & $\begin{array}{l}\text { - Alegria, Alegria (Caetano Veloso) } \\
\text { - Domingo no Parque (Gilberto Gil) } \\
\text { - Tropicália (Caetano Veloso) }\end{array}$ \\
\hline
\end{tabular}

Fonte: Elaborado pelos autores (2020). 


\section{Intervenções artísticas no espaço escolar}

As Artes Visuais envolvem diferentes tipos de imagens e merecem lugar de destaque no contexto escolar ${ }^{1}$. Nesse sentido, Samain $(2018$, p. 22) salienta que toda imagem nos oferece algo para pensar e que imagens "são poços de memórias e focos de emoções, de sensações, isto é, lugares carregados precisamente de humanidade”. Reconhecendo a potência das imagens enquanto formas de representação e instrumento pedagógico, realizamos intervenções artísticas em diferentes espaços do COLUN/UFMA, na perspectiva de provocar reflexões sobre temáticas como diferença, gênero, violência e intolerância política.

Assumindo a possibilidade de construção de um currículo dinâmico, foi criado o projeto "Intervenções artísticas no COLUN: Educação, diversidade e desenvolvimento”, resultado do interesse de estudantes do Ensino Médio do COLUN, que estudaram a linguagem das Artes Visuais no primeiro ano e desejaram usar a arte como forma de expressão e transformação no ambiente escolar ${ }^{2}$. Além disso, as intervenções artísticas foram escolhidas pelo seu poder visual e por possibilitarem a reflexão sobre a realidade educativa através da linguagem da arte contemporânea, destacando-se seu caráter provocativo, eclético e híbrido.

Quadro 2 - Intervenções artísticas realizadas

\begin{tabular}{|l|l|}
\hline & \multicolumn{1}{|c|}{$2018-2019$} \\
\hline & $\begin{array}{l}\text { Resistência pela existência - 20.10.2018 } \\
1^{a} \text { intervenção artística, no corredor do COLUN/UFMA, São Luís - Maranhão }\end{array}$ \\
\hline & $\begin{array}{l}\text { O que é ser homem? - 22.11.2018 } \\
2^{a} \text { intervenção artística, no pátio do COLUN/UFMA, São Luís - Maranhão }\end{array}$ \\
\hline & $\begin{array}{l}\text { Diferenças - 15.10.2019 } \\
3^{a} \text { intervenção artística, nas janelas do COLUN/UFMA, São Luís - Maranhão }\end{array}$ \\
\hline
\end{tabular}

Fonte: Elaborado pelos autores (2020).

O processo envolveu diferentes etapas, desde a escolha do tema, a realização de estudos acompanhados de debates, oficinas e rodas de conversa acerca do assunto, até, finalmente, a fase de criação, em que

1. É preciso esclarecer que imagem é um conceito de múltiplos significados. Contudo, compreendemos a imagem como sinônimo de representação física ou mental e usamos essa palavra para descrever desde uma garatuja até um desenho animado (JOLY, 1996). As intervenções artísticas consistem em manifestações contemporâneas que interagem com o espaço em que se localizam, modificando o ambiente e o cotidiano naquele local, por meio de diferentes tipos de imagens e técnicas. Tais características motivaram sua utilização como método de exposição dos temas escolhidos.

2. O conceito de Artes Visuais se ampliou e, ao que tradicionalmente definia-se como o desenho, a pintura, a gravura, a escultura, o desenho industrial e a arquitetura, hoje incorporaram-se mais modalidades artísticas, haja vista que são percebidas, ainda que diferentemente, pela sua visualidade. Atualmente, entende-se Artes Visuais enquanto o conjunto de expressões artísticas que englobam desde as tradicionais, mencionadas anteriormente, até as mais novas modalidades, como a fotografia, as artes gráficas, os quadrinhos, a publicidade, o cinema, a computação, o vídeo, a televisão e a performance (BRASIL, 1997). Há também o Teatro e a Dança, que são marcados pela visualidade, mas, no currículo escolar, constituem linguagens artísticas específicas. 
foram escolhidos os materiais e as técnicas para elaboração das intervenções. Iniciado em 2018, o projeto realizou quatro intervenções artísticas na escola e participou de cinco eventos: na Mostra Pedagógica do II Seminário dos Institutos, Escolas e Colégios de Aplicação, Regional Amazônia Legal, Nordeste e Centro Oeste, no COLUN/UFMA, em São Luís; na Mostra Científica da VI Semana de Meio Ambiente, no COLUN/UFMA, em São Luís; no Projeto de Intercâmbio no Colégio de Aplicação da UFPE, no Recife; no II Seminário Interdisciplinar de História das Mulheres, Gênero e Sexualidade, na UFMA, em São Luís; e na Feira Brasileira de Colégios de Aplicação e Escolas Técnicas, na UFMG, em Belo Horizonte.

Vale ressaltar que, através de suas ações, o projeto contribuiu para o desenvolvimento de um olhar artístico e humanitário, transformando a arte em ponte para um ambiente escolar mais inclusivo, crítico e sensível, pois buscou pensar na diferença, na diversidade, na importância da educação, na valorização do patrimônio e nas dificuldades enfrentadas no ambiente escolar. É desafiador introduzir questões tão complexas na educação básica. Contudo, vivenciamos a necessidade de que algo seja feito diante deste contexto político em que cada vez mais os discursos de intolerância e ódio são legitimados e repetidos em diferentes esferas da vida social.

\section{Grupo de Teatro Entrecena e participação no Festival de Teatro Estudantil de Pindamonhangaba - SP (FESTIL)}

O Grupo ENTRECENA foi fundado em 2010, com alunos do sexto ano do Ensino Fundamental do COLUN/UFMA. Posteriormente se expandiu para o Ensino Médio e, a partir do ano de 2011, dedicou-se às apresentações na própria escola. Foi contemplado em 2015, no Festival de Teatro Estudantil (FETO), na cidade de Belo Horizonte. No processo de construção dos espetáculos, houve engajamento de professores de Teatro, Artes Visuais e Música em suas respectivas linguagens, tendo oportunidade de momentos específicos (demandas da sua linguagem no/para o grupo) e momentos conjuntos (ensaios gerais).

Iniciando sua participação no FESTIL no ano de 2017, o grupo apresentou o espetáculo A história é uma istória e o homem é o único animal que ri, de Millôr Fernandes. Na ocasião, foi premiado como melhor espetáculo nas categorias júri popular e júri técnico; prêmios destaques com melhor sonoplastia e melhor encenação coletiva.

Quadro 3 - Ficha técnica: A história é uma istória e o homem é o único animal que ri

\begin{tabular}{|l|l|}
\hline \multicolumn{2}{|c|}{ Ficha técnica: A história é uma istória e o homem é o único animal que ri } \\
\hline Sinopse & $\begin{array}{l}\text { Texto escrito na década de 1980, em São Luís, no contexto de implementação das } \\
\text { grandes indústrias e despejos na região Itaqui-Bacanga (local onde também o COLUN } \\
\text { se localiza). O texto e músicas são de Josias Sobrinho e Tácito Borralho. Sua narrativa é } \\
\text { atravessada pela mitologia da Serpente e Dom Sebastião. Apesar da temporalidade } \\
\text { da escrita, a obra ainda é lúcida e atual. Povos e comunidades tradicionais resistem } \\
\text { como forma cotidiana de sobre(viver). }\end{array}$ \\
\hline Autor & Millôr Fernandes \\
\hline Direção & Prof. Jorge Milton \\
\hline Iluminação & Prof. Jorge Milton \\
\hline Contrarregra & Profa. Beatriz Sousa \\
\hline Elenco & $\begin{array}{l}\text { 9 Estudantes do Ensino Médio: Erick Oliveira, Jorge Fernando, Miriam Nunes, Rafael } \\
\text { Cavalcante, Hélen Clarice, Laíza Danielle, Natália Lemos, Yasmin Oliveira e Rafaela } \\
\text { Alves. }\end{array}$ \\
\hline Direção Musical & Prof. Micael Carvalho \\
\hline
\end{tabular}

Fonte: Elaborado pelos autores (2020).

Aves de Arribação foi um espetáculo apresentado no ano de 2018 conquistando o primeiro lugar pelo júri técnico e pelo júri popular. Ainda, recebeu as premiações de melhor sonoplastia, melhor figurino e indicações de melhor direção e atuações. 
Quadro 4 - Ficha técnica: Aves de Arribação

\begin{tabular}{|c|c|}
\hline \multicolumn{2}{|r|}{ Ficha técnica: Aves de Arribação } \\
\hline Sinopse & $\begin{array}{l}\text { A ilha flutuante está prestes a entrar em um momento decisivo: as eleições. Vivendo em } \\
\text { um âmbito desigual e subjugados pelos pássaros de cima, as aves rasteiras se veem diante } \\
\text { de um dilema que os força a repensar suas atitudes perante seus representantes, decidindo } \\
\text { por então mostrar seu poder de reação visando alcançar sua autonomia. O texto se passa } \\
\text { em um local onde há dois planos, sendo um com os pássaros de cima representando a } \\
\text { elite e outro com os pássaros de baixo representando a classe operária. No decorrer do } \\
\text { texto há uma tentativa de dominação dos pássaros de cima sobre os pássaros de baixo, e } \\
\text { os pássaros de baixo por sua vez travam uma resistência com os pássaros de cima pela ilha } \\
\text { que habitam e corre sério risco de sofrer consequências drásticas. }\end{array}$ \\
\hline Autor & Aldo Leite \\
\hline Direção & Prof. Jorge Milton \\
\hline Iluminação & Raylton da Conceição (convidado) e Lucas de Paula (Estudante do Ensino Médio) \\
\hline $\begin{array}{l}\text { Consultoria dos } \\
\text { figurinos e adereços }\end{array}$ & João Ewerton (Artista Plástico) \\
\hline Cenário & Adrianna Karlen (Artista Plástica e Colaboradora do Projeto) \\
\hline Coreografia & Tânia Cristina Costa Ribeiro (Profa. do Dpto. de Artes Cênicas da UFMA) \\
\hline Direção Musical & Prof. Micael Carvalho \\
\hline Sonoplastia & Prof. Micael Carvalho, Rafaela Penha e Douglas Borges. \\
\hline $\begin{array}{l}\text { Contrarregra e } \\
\text { Maquiagem }\end{array}$ & Prof $^{a}$. Beatriz Sousa \\
\hline Elenco & $\begin{array}{l}12 \text { alunos do Ensino Médio: Alexsandro Sousa Martins, Ana Clara Silva Moreira, } \\
\text { Benjamim Alves de Aguiar, Camille Leite Gomes, Débora Marques da Silva, Douglas } \\
\text { Vinicius Coelho Borges, Mariana Campos Barros, Nathália Rocha Paulino, Rafaela Alves } \\
\text { Penha, Rayssa Silva de Sousa, Wilgner Vander Vieira Lindoso, Yasmin Oliveira Ferreira. }\end{array}$ \\
\hline
\end{tabular}

Fonte: Elaborado pelos autores (2020).

João Paneiro foi um espetáculo apresentado no ano de 2019, terceiro ano consecutivo de apresentação do grupo no Festival. O grupo levou as premiações: $3^{\circ}$ lugar na categoria "Teatro na Escola", Melhor Sonoplastia e Melhor "Atriz Coadjuvante".

\section{Quadro 5 - Ficha técnica: João Paneiro}

\begin{tabular}{|l|l|}
\hline \multicolumn{2}{|c|}{ Ficha técnica: João Paneiro } \\
\hline Sinopse & $\begin{array}{l}\text { Escrito no contexto da década de 1980, em São Luís, de implantações das grandes } \\
\text { indústrias e despejos na região Itaqui-Bacanga (local onde também se localiza o } \\
\text { Colun). O texto e músicas são de Josias Sobrinho e Tácito Borralho. Sua narra- } \\
\text { tiva é atravessada pela mitologia com a lenda da Serpente e Dom Sebastião. João } \\
\text { Paneiro é um trabalhador rural que resiste ao projeto de despejo e reestruturação } \\
\text { das cidades no contexto da industrialização. A obra é carregada de regionalismos } \\
\text { linguísticos e musicalidades maranhenses. Apesar da temporalidade da escrita, } \\
\text { a obra ainda é lúcida e atual. Povos e comunidades tradicionais resistem como } \\
\text { forma cotidiana de sobre(viver). }\end{array}$ \\
\hline Autor & Tácito Borralho e Josias Sobrinho \\
\hline Direção & Prof. Jorge Milton \\
\hline Iluminação & Lucas de Paula (Estudante do 3o ano do Ensino Médio) \\
\hline Contrarregra/Artista & Adrianna Karlen (Artista Plástica e Colaboradora do Projeto) \\
\hline Plástica & Prof. Micael Carvalho \\
\hline Elenco & $\begin{array}{l}\text { 9alunos do Ensino Médio: Guilherme Reis, Ana Beatriz Araújo, Vitoria Elen, } \\
\text { Mateus Mesquita, Raquel Aguiar, Jéssica Souza, Ana Rafaele Oliveira, Douglas } \\
\text { Vinícius, Samuel Passos) e 1 aluno do Ensino Fundamental: Lyam Ferreira. }\end{array}$ \\
\hline
\end{tabular}

Fonte: Elaborado pelos autores (2020). 
Citamos as premiações compreendendo como reconhecimento do processo de montagem nos espetáculos, ressaltando que a ênfase da participação e da construção artístico-educativa dos discentes e docentes envolvidos. Destacamos que os festivais de Teatro Estudantil são espaços de formação artística com uma capacidade ampla de imersão em diferentes propostas em Arte Cênica, com diálogos que alcançam outras expressividades da Arte. Em tempos como este, insistir nesses processos torna-se fundamentalmente necessário para combater o desprezo, a ignorância e a censura política às expressões artísticas.

\section{Considerações finais}

Como resultados obtidos, destacamos a maior afetividade dos discentes participantes dos espaços artísticos, construindo potencialidades de criação e autonomia. Ainda, percebemos o desenvolvimento de expressividades individuais e coletivas a partir da discussão que envolve uma territorialização ampliada do espaço artístico na escola, expandindo assim, os sentidos da Arte na Escola. Indicamos a necessidade do trabalho com a linguagem de Dança com um(a) profissional habilitado(a) na linguagem para completar o quadro docente da instituição e ampliar o trabalho artístico-pedagógico no COLUN. Esta demanda se configura como fundamental, dado o contexto da necessidade de adequação do componente Arte, contemplando todas as expressividades artísticas, conforme a Lei 13.278 de 2016, que inclui as Artes Visuais, a Dança, a Música e o Teatro nos currículos dos diversos níveis da educação básica.

\section{Referências}

BRASIL. Ministério da Educação e do Desporto. Secretaria de Educação Fundamental. Parâmetros curriculares nacionais: Arte. Brasília, DF: MEC; SEF, 1997.

CANDAU, Vera Maria Ferrão. Diferenças culturais, cotidiano escolar e práticas pedagógicas. Currículo sem Fronteiras, Portugal, v. 11, n. 2, p. 240-255, jul./dez. 2011.

GIROUX, Henry; SIMON, Roger. Cultura popular e pedagogia crítica: a vida cotidiana como base para o conhecimento curricular. In: MOREIRA, Antonio Flavio; TADEU, Tomaz (org.). Currículo, cultura e sociedade. 12. ed. São Paulo: Cortez, 2011. p. 107-140.

JOLY, Martine. Introdução à análise da imagem. Campinas: Papirus, 1996.

MOREIRA, Antonio Flavio; TADEU, Tomaz (org.). Currículo, cultura e sociedade. 12. ed. São Paulo: Cortez, 2011.

SAMAIN, Etienne. As imagens não são bolas de sinuca. In: SAMAIN, Etienne (org.). Como pensam as imagens. Campinas: Editora da Unicamp, 2018. p. 21-36.

SILVA, Tomaz Tadeu da. Documentos de identidade: uma introdução às teorias do currículo. Belo Horizonte: Autêntica, 1999.

Data de submissão: 19/06/2020

Data de aceite: $29 / 07 / 2020$ 